\title{
Editorial: PPP at Ten
}

\author{
David Robinson ${ }^{1}$ and Peter Wells ${ }^{2 *}$ \\ 1 University of Sheffield \\ 2 Sheffield Hallam University
}

\section{Looking back}

PPP Online was launched ten years ago: before the financial crisis, before austerity, before the EU referendum in the UK, and before the rise of post truth politics. PPP was launched on the premise of a two related challenges. Firstly, to social scientists to engage in policy and political debate, and secondly to policy communities to engage with academic ideas and critique. The journal was intended to act as a bridge between the two by providing a forum for debate.

The focus on people, place and policy reflected a concern that an explicit understanding of the geography of places, how people interact with place and the lived experience of residents of neighbourhoods was often absent in the making and implementation of policy. In 2017 these themes and the interactions between them appear even more important.

PPP has published articles across all of these themes. It has offered a critique of policies and accounts of the impact of policies on people and places. Notable examples include the publication of special issues on topics which include family policy, energy policy, fuel poverty, austerity and the third sector, and Roma integration in the UK. These issues hopefully provided key reference points and analysis of complex policy issues.

The journal has also offered more normative accounts in the form of critiquing policy narratives and then advancing possible policy alternatives. One of the most prominent, and still most downloaded paper, is lan Cole's paper on the future of social housing in England (Cole, 2007). In this paper, lan articulated an agenda to garner support for social housing which was sensitive to the needs to different places yet served to underpin wider policy goals, whether in terms of labour markets or support through the life course. In a similar vein Ruth Lupton provided a defence of neighbourhood policies as a component of wider social and economic policies - but not as the panacea in rejuvenating poor places (Lupton, 2013).

\section{Looking Forward}

Policy making in 2017 is often characterised by a series of what appear intractable crises from ecological crisis brought by climate change to humanitarian crisis brought by conflict between states, faiths and ideologies. Indeed, and as the rise of populist and post truth agendas attest there is an apparently intractable crisis in the legitimacy of the dominant policy making system in Western Europe and North America. Against 
these backdrops the consensus which appeared to hold sway and hold nation states together in the post-World War Two period appear now to face real and existential threats to their ongoing existence. These threats are perhaps in most evidence in the United Kingdom which has provided the focus for the majority of scholarship in PPP.

There are two related responses social science can make to such an array of challenges. One is to be guided by the politics of fate: that social scientists are simply commentators and analysts of the events which unfold around them. Such commentary and analysis is of course vital but it can fail to recognise the power of debate and of ideas themselves. The second response is the approach of engagement and articulation of alternative ideas, concepts and ways of making sense of the world. Rhetorically at least, politicians since Bobby Kennedy in the 1960s have referred to this as the politics of hope. It is based on assumptions that although crises may be of human making, that solutions may come from human ingenuity.

Concluding this editorial on a reflection on the future of publishing may look an overtly narrow and limited response given the case made for ingenuity and for hope. In 2007 PPP was a rare journal: it was published online and it was published for free with no charges made to either authors or readers of articles. It is still a free journal but it is now less rare. Journal papers compete for our precious time against multiple channels of information including social media. The time of policy makers is even more limited. What will distinguish PPP in the coming years is its commitment to the quality and distinctiveness of the articles it publishes. However, this alone, will not garner policy interest. With this in mind we are launching a new series of papers from 2018 - PPP Alternatives.

\section{PPP alternatives}

PPP Alternatives are intended to advance either wholly new policy propositions or new ways of addressing what appear intractable policy problems. The intention is to tie the rigour of social science analysis with the wisdom of practitioners and policy makers, to articulate ideas and garner support for policy ideas. PPP Alternatives will not be limited to specific geographic scales or groups although all papers will consider the implications for people and places. Papers should be limited 2000 words but should include references, links to further reading and to evidence. We will also undertake through use of social media and other channels to promote each PPP Alternatives Paper.

* Correspondence address: Professor Peter Wells, CRESR, Sheffield Hallam University, Unit 10 Science Park, Howard Street, Sheffield, S1 1WB. Email: p.wells@shu.ac.uk

\section{References}

Cole, I. (2007) What future for social housing in England? People, Place and Policy Online, 1, 1, 3-13.

Lupton, R. (2013) What is neighbourhood renewal policy for? People, Place and Policy Online, 7, 2, 66-72. 